\title{
Abdominal Access for Shoulder Dystocia as a Last Resort - a Case Report
}

\section{Abdominaler Zugang bei Schulterdystokie als Ultima Ratio - ein Fallbericht}

Authors

Affiliations
A. Enekwe ${ }^{1}$, R. Rothmund ${ }^{2}$, B. Uhl ${ }^{1}$

${ }^{1}$ Gynaecology Deparment, St-Vinzenz-Hospital Dinslaken, Dinslaken, Germany

${ }^{2}$ University Hospital of Obstetrics and Gynaecology, Tübingen, Germany

\section{Key words \\ - shoulder dystocia \\ - abdominal rescue \\ - Erb's palsy \\ Schlüsselwörter \\ - Schulterdystokie \\ - abdominaler \\ Rettungsversuch \\ - Armplexusparese}

received $\quad 24.2 .2012$

revised $\quad 1.5 .2012$

accepted $\quad 6.5 .2012$

Bibliography

DOI http://dx.doi.org/

10.1055/s-0032-1314962

Geburtsh Frauenheilk 2012; 72:

634-638 @ Georg Thieme

Verlag KG Stuttgart · New York . ISSN 0016-5751

\section{Correspondence}

Antje Enekwe, PhD

St-Vinzenz-Hospital Dinslaken

Gynaecology Department

Dinslaken

Germany

Antje.Enekwe@web.de

\section{Abstract \\ $\nabla$}

Shoulder dystocia is the term used to describe failure to progress in labour after the head has been delivered due to insufficient rotation of the shoulders. It is unpredictable and cannot be prevented by the midwife or the obstetrician. We report here on a severe case of shoulder dystocia, where delivery of the shoulder was finally achieved through direct pressure on the anterior shoulder after laparotomy and uterotomy with concurrent vaginal Woods screw manoeuvre and was followed by vaginal delivery. The patient presented risk factors like maternal obesity and administration of labour-inducing drugs. After different manoeuvres like McRoberts manoeuvre and several manoeuvres for internal rotation were carried out unsuccessfully, an emergency laparotomy was performed. The newborn was in need for reanimation and artifical ventilation postpartum but recovered fast during the following days. An Erb's palsy of the posterior arm improved during the hospital stay. The German Guideline of the DGGG [8] recommends a risk management plan and regular training to all birth attendants for obstetric clinics. Beside the vaginal manoeuvres one should have at least theoretical expertise in operative manoeuvres to be able to perform them in emergency cases.

\section{Introduction}

Shoulder dystocia is the term used to describe failure to progress in labour after the head has been delivered due to insufficient rotation of the shoulders. It is necessary to differentiate between high shoulder dystocia where the shoulder is directly above the pelvic inlet, and low shoulder dystocia where the shoulders remain stuck in the pelvic cavity in the anteroposterior diameter [1].

\section{Zusammenfassung}

$\nabla$

Die Schulterdystokie beschreibt einen Geburtsstillstand nach Geburt des Kopfes aufgrund unzureichender Schulterdrehung. Das Ereignis trifft die geburtshilflich tätige Person in der Regel völlig unerwartet. Es wird hier über einen Fall einer schweren Schulterdystokie berichtet, bei dem die Schulterlösung durch direkten Druck auf die vordere Schulter nach Laparotomie und Uterotomie bei gleichzeitigem Woods-Screw-Manöver von vaginal mit anschließender vaginaler Entbindung gelang. Die Patientin wies eine Adipositas und die Gabe von wehenfördernden Mitteln als Risikofaktoren auf. Nach erfolgloser Ausführung des McRoberts-Manövers und diverser Manöver zur inneren Rotation wurde eine Notlaparotomie durchgeführt. Das Neugeborene musste direkt postpartal reanimiert und für einige Stunden beatmet werden, erholte sich im weiteren Verlauf jedoch rasch. Eine Erb'sche Armplexuslähmung des hinteren Armes besserte sich während des stationären Aufenthalts. Die Leitlinie der DGGG [8] sieht einen Risikomanagement-Plan sowie regelmäßiges Training aller beteiligten Personen für alle geburtshilflich tätigen Kliniken vor. Hierbei sollten nicht nur die vaginalen Manöver geübt werden, sondern auch zumindest theoretische Kenntnisse der operativen Manöver vermittelt werden, um sie im Notfall anwenden zu können.

The diagnosis is usually made based on manual examination.

Shoulder dystocia is unpredictable and cannot be prevented by the midwife or the obstetrician. Most cases of shoulder dystocia are delivered safely using well-known manual manoeuvres, and delivery is by vaginal birth. In the few cases where this is not possible, the midwife must quickly decide on the appropriate method with which to release the shoulder; this may require 
an operative intervention and is therefore associated with an increased risk of morbidity for mother and baby and may not have been practiced previously.

We report here on a severe case of shoulder dystocia in our clinic. Delivery of the shoulder was finally achieved through direct pressure on the anterior shoulder after laparotomy and uterotomy with concurrent vaginal Woods' screw manoeuvre, and was followed by vaginal delivery.

\section{Case Report}

A 30-year-old woman presented to the labour room with the onset of contractions in her 39th week of pregnancy after an uneventful pregnancy. This was her second full-term pregnancy.

The woman had last given birth 2 years earlier. According to the hospital records, the previous birth was normal. The first child had a birth weight of $3780 \mathrm{~g}$, a length of $51 \mathrm{~cm}$, and a head circumference was $34 \mathrm{~cm}$, (i.e. all were within normal ranges). Apgar scores were $8-10-10$ and arterial $\mathrm{pH}$ was 7.24 . A grade 2 perineal tear was sutured after birth. The postpartum period was uneventful.

At the most recent presentation the patient was obese, with a body weight of $99 \mathrm{~kg}$, a height of $159 \mathrm{~cm}$ and a calculated body mass index (BMI) of 39. Ultrasound done on admission showed a vital foetus in cephalic presentation, 2nd position, with a normal quantity of amniotic fluid; biometric measurements gave an estimated foetal weight of $3800 \mathrm{~g}$ (calculations according to Hadlock [2]). On initial examination, the cervical length was $2 \mathrm{~cm}$ in a mid-sacral position, and the cervix was $2 \mathrm{~cm}$ dilatated; the head was $2 \mathrm{~cm}$ above the interspinal level, and the amniotic sac had not ruptured.

An epidural catheter was placed for epidural analgesia two hours after admission at the patient's request. Initially, the birth appeared to be progressing normally. When the contractions decreased, oxytocin administration $(15 \mathrm{ml} / \mathrm{h}, 6 \mathrm{IE}$ in $500 \mathrm{ml}$ glucose $5 \%$ ) was started 10 minutes after placing the epidural catheter and administration was later briefly increased to $30 \mathrm{ml} / \mathrm{h} 30 \mathrm{~min}-$ utes before the head was born. The records provide no information on bladder emptying after the epidural catheter was placed. The head was born after 4.5 hours. When this was not followed by the shoulders and the head remained retracted, pressing tightly against the vulva ("turtle sign"), a mediolateral episiotomy was done. This still did not result in birth of the body. The attendant physician diagnosed a shoulder dystocia. Oxytocin infusion was immediately stopped. The McRoberts' manoeuvre was then performed together with suprapubic pressure. This was followed by manoeuvres to internally rotate the baby (Woods' screw manoeuvre, Rubin manoeuvre) and delivery of the posterior arm, which were performed correctly but were unsuccessful. General anaesthesia was then administered. A further attempt at internal shoulder rotation after the maternal muscles had relaxed was also unsuccessful. Nine minutes after delivery of the head, an emergency laparotomy was performed via Pfannenstiel incision through all layers and uterotomy to obtain direct access to the baby and the trapped shoulder. Pressure was exerted on the anterior left trapped shoulder with simultaneous pressure exerted vaginally against the posterior right shoulder (Woods' screw manoeuvre) ( Figs. 1 to 3). This manoeuvre rotated the infant sufficiently to deliver the anterior shoulder, and the baby was delivered vaginally 11 minutes after the birth of the head. Arterial $\mathrm{pH}$ on delivery was 7.12 , and base excess was $-12 \mathrm{mmol} / \mathrm{l}$. The baby
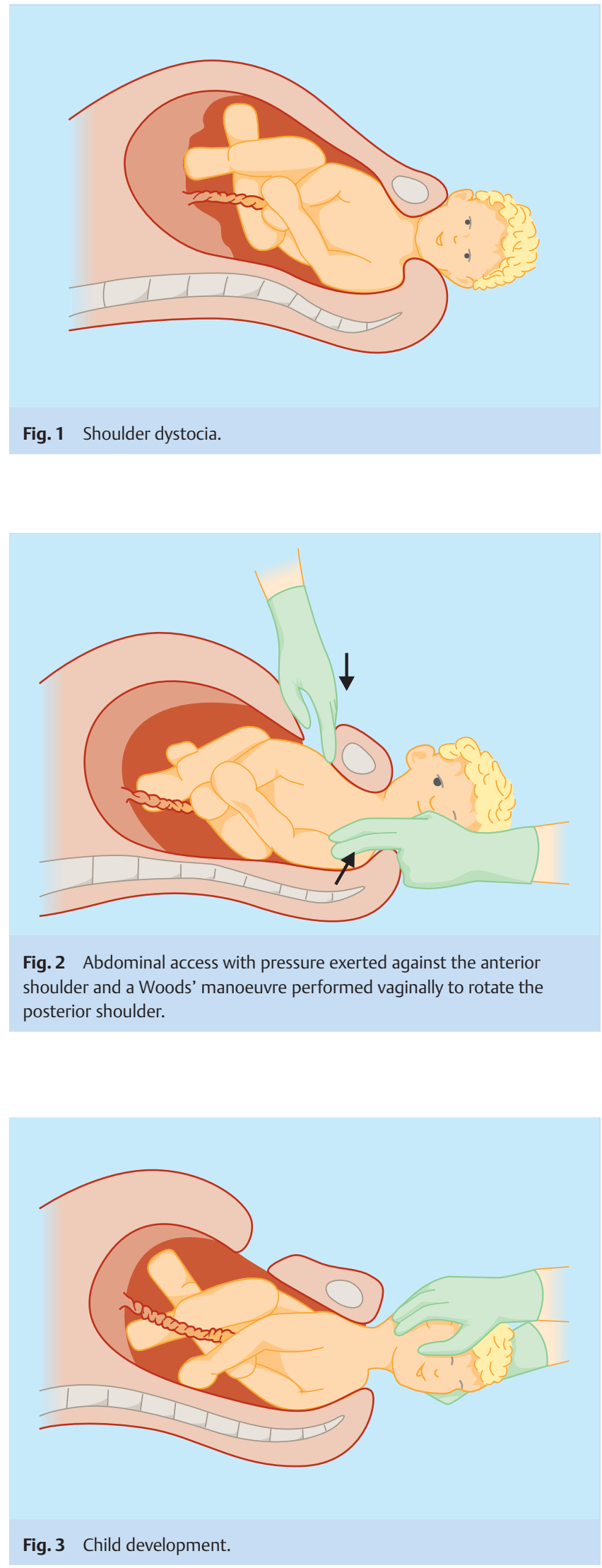
weighed $4180 \mathrm{~g}$ at birth with a height of $58 \mathrm{~cm}$ and a head circumference of $34.5 \mathrm{~cm}$. The infant was initially born without vital signs; the skin colour was pale, the muscle tone was flaccid, and the infant had apnoea and asystolia. The infant was immediately given to the attendant neonatal clinician. Nose, throat and stomach were suctioned, and bag and mask ventilation were started immediately. When asystolia persisted for more than 30 seconds, cardiac massage was initiated until the heart began beating. The infant was intubated at 3 minutes. At age 10 minutes the skin turned rosy and the baby was transferred to the neonatal intensive care unit. Neonatal lactate was $66 \mathrm{mg} / \mathrm{dl} 4$ hours after birth and decreased to $39 \mathrm{mg} / \mathrm{dl} 6$ hours post partum. During the infant's subsequent stay in hospital, a perinatal infection with Staphylococcus epidermidis and Enterococcus faecalis was successfully treated with cefotaxime and gentamycine. Erb's palsy of the right arm (the posterior arm during the birth) was noted; however this had already began to improve during the infant's stay in hospital. A cut on the infant's left calf caused by the uterotomy was treated conservatively. The infant did not develop hypoxic ischaemic encephalopathy. The baby recovered after treatment in the neonatal unit, and was discharged home 16 days later. Data from subsequent paediatric examinations showed that the infant continued to develop normally. The arm palsy resolved completely.

Other than the episiotomy mother suffered no additional injuries during delivery. Haemoglobin at admission was $11.1 \mathrm{~g} / \mathrm{dl}$ and was $8.7 \mathrm{~g} / \mathrm{dl}$ post partum. As the mother was asymptomatic, oral iron substitution was considered sufficient. Both the gynaecologist and the paediatrician had several talks about the birth and the available follow-up care with the patient and her husband during the patient's stay in hospital. The mother was given cefazoline and metronidazole as antibiotic prophylaxis until discharge. She was discharged home on the 5th day postoperatively.

Four years later, the patient gave birth again. Due to the mother's previous history, the infant was born by caesarean section after prior consultation with the mother. There were no complications.

\section{Discussion}

$\nabla$

The reported incidence of shoulder dystocia in the literature ranges between 0.3 and $1.6 \%[1,3]$. The incidence increases significantly depending on birth weight ( Fig.4, after Berle et al. 2009 [3]).

Around half of all cases with shoulder dystocia occur with infants who weigh less than $4000 \mathrm{~g}$ (Berle et al.: 44\% [3]; Stein et al.: $40.5 \%[4])$.

Numerous risk factors for shoulder dystocia have been reported in the literature $[1,3-6]$. They include maternal risk factors such as obesity (BMI > 30), maternal weight gain of more than $15 \mathrm{~kg}$ during pregnancy, diabetes mellitus, multiparity, late-term birth (more than 7 days late), induction of labour, shoulder dystocia at anamnesis, and pelvic anomalies. Foetal risk factors include macrosomia, foetal head circumference of more than $35 \mathrm{~cm}$, and a difference between biparietal and thoracic diameters of more than $14 \mathrm{~mm}$, in other studies of more than $15 \mathrm{~mm}$ [7]. Intrapartum risk factors include a protracted expulsion phase, a very quick expulsion phase when the shoulders have no time to rotate properly when reaching the pelvic inlet, vaginal operative delivery and the administration of labour-inducing drugs.

Our patient presented with several risk factors including maternal obesity (BMI of 39) and the administration of labour-inducing

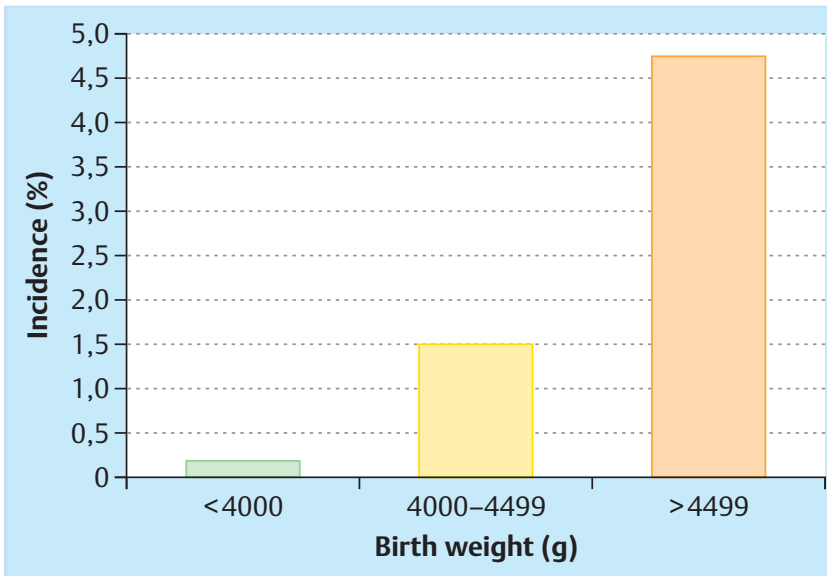

Fig. 4 Incidence of shoulder dystocia as a function of birth weight (after Berle et al. [3], $n=222519$ births).

drugs. The expulsion phase until the head was born was only 13 minutes. There is no data on maternal weight gain during pregnancy, and no sonographic images showing a difference between foetal biparietal and thoracic diameters are available.

Prepartally, the birth weight was estimated to be $3800 \mathrm{~g}$, based on sonographic images. The actual birth weight was $4180 \mathrm{~g}$ and was thus within the tolerance range of $10 \%$.

The guideline of the German Society for Gynaecology and Obstetrics (DGGG) on shoulder dystocia [8] recommends offering patients elective caesarean section if the infant has an expected birth weight of $4500 \mathrm{~g}$ and over. As macrosomia was initially excluded in the case described here, caesarean section was not discussed. Moreover, the initial phase of labour was so uneventful that there was no indication for caesarean section at any time. As described above, the diagnosis of shoulder dystocia is made based on manual examination. During examination, the position of the shoulder is palpated. Additional clinical indications such as the "turtle sign" mentioned above may be present and will support the diagnosis.

Once shoulder dystocia had occurred, attempts were made to deliver the shoulder using a number of different manipulations. The first attempt consisted of a McRoberts' manoeuvre, which was then combined in the 2nd attempt with suprapubic pressure. Subsequently, the Woods' screw manoeuvre, the Rubin manoeuvre, and an attempt to deliver the posterior arm were carried out as recommended in the DGGG guideline [8], but all attempts were unsuccessful.

Various studies have investigated the success rates of individual manoeuvres. In their study collective (205 cases of shoulder dystocia), Leung et al. [9] reported a success rate of $25 \%$ for the McRoberts' manoeuvre combined with suprapubic pressure and an associated rate of brachial plexus palsies of $7.8 \%$. McFarland et al. [10] (276 cases of shoulder dystocia) reported a success rate of $58 \%$ and a neonatal injury rate of a $12.9 \%$. After the additional application of the Woods' screw or Rubin manoeuvre the success rate of Leung et al. [9] was $72 \%$ with no increase in neonatal morbidity. McFarland et al. [10] showed that the number of manoeuvres required to resolve the dystocia was directly correlated with the incidence for neonatal injury (7.7\% after 1-2 manoeuvres; $25 \%$ after 3 manoeuvres). The guideline of the DGGG [8] suggests creating an episiotomy or extensively enlarging an existing episiotomy as an additional measure in shoulder dystocia. However, 
in a recent study by Paris et al. [11] this did not help prevent any brachial plexus palsies. Thus, this is not a procedure which should be used as a standard approach. In the case described here, an episiotomy was cut without achieving the desired success.

The DGGG guideline [8] offers no further recommendations regarding other manipulations to be performed if the proposed manoeuvres should fail. In such cases, as in the case described here, possible alternative procedures include the Gaskin manoeuvre, cleidotomy, the Zavanelli manoeuvre, symphysiotomy or even transabdominal shoulder rotation.

According to Gnirs [1], cleidotomy is not certain to result in a reduction in shoulder diameter with delivery of the shoulder, as usually it leads to an incomplete subperiostal fracture ("green branch fracture") with insufficient reduction of the width of the shoulders.

In 1999, Sandberg [12] published a review article which reported a success rate of $77.3 \%$ for the Zavanelli manoeuvre ( 84 Zavanelli manoeuvres for shoulder dystocia). Neonatal complications included clavicular fracture, humeral fracture, Erb's palsy, quadriplegia, brain damage, mental retardation, various cerebral palsies and even mortality. In this study the Zavanelli manoeuvre was described as easy to perform. In contrast, Vollebergh et al. [13] published a review in 2000 (70 Zavanelli manoeuvres for shoulder dystocia) of the Zavanelli manoeuvre and included a case report on severe shoulder dystocia. They pointed out that the manoeuvre is not easy to perform and could result in severe maternal and neonatal morbidity.

A few case reports have described the use of symphysiotomy for shoulder dystocia $[14,15]$. This method was commonly used after failure of a Zavanelli manoeuvre. It is therefore not possible to estimate the success rate. Reported maternal complications include vesicovaginal fistulas, urethral injury, urinary incontinence, difficulties in walking, pain, infections and haemorrhage [1].

Transabdominal shoulder rotation with subsequent vaginal delivery has been previously described in 2 cases, both performed after the failure of a previously attempted Zavanelli manoeuvre $[16,17]$. Both case reports describe how, after hysterotomy, direct pressure was exerted against the anterior shoulder to rotate it into the oblique diameter but without success. Finally, the posterior arm was rotated and the birth was completed vaginally.

In the case report by O'Leary et al. [16] the time from delivery of the head until delivery of the whole body was 21 minutes (headbody delivery interval = HBDI). The Apgar score was 1-1-5. The infant was intubated for one day and ventilated and suffered from seizures in the immediate postpartum period. Six months after delivery the infant was described as developing normally. In the 2nd case report by O'Shaughnessy [17] the HBDI was 14 minutes. The Apgar score was $0-0-1$. Post partum, the infant suffered from severe hypoxic ischaemic encephalopathy. There were no fractures but the infant subsequently had Erb's palsy of the anterior trapped arm.

In our case, the HBDI was shorter than in both cases described above. The infant in our case did not suffer from hypoxic ischaemic encephalopathy. Transient Erb's palsy of the posterior arm was diagnosed post partum.

In all three case reports it is not clear whether the reported neonatal morbidity was caused by the transabdominal shoulder rotation itself or had already occurred in the run-up to the rotation as a consequence of other manoeuvres. In our case, the anterior shoulder was not affected by plexus palsy but the posterior shoulder was. Hankins and Clark also described a case with pos- terior arm plexus palsy after a vaginal birth where only the McRoberts' manoeuvre had been performed [18]. They suspected that the combination of the strong propulsive forces during birth and a shoulder trapped under the sacral promontory led to traction on the plexus, resulting in the impairment.

Additional neonatal complications after shoulder dystocia include lower arm paralysis, which occurs less often than upper plexus paralysis, elevated hemidiaphragm due to paralysis of the phrenic nerve, clavicular and humeral fractures, haematoma of the sternocleidomastoid muscle resulting in torticollis, and foetal hypoxia leading to hypoxic ischaemic encephalopathy $[19,20]$. Maternal complications range from injury of the birth canal to uterine rupture with haemorrhage $[1,19]$. Other authors report on subsequent maternal infections and atony of the bladder [1]. Psychological counselling should be offered to the mother if the birth was experienced as traumatic. Some studies report postnatal depression, posttraumatic stress disorder and difficulties in mother-child bonding [20]. Recommendations for mothers include pelvic floor training as part of a postnatal exercise regime and potentially a lifelong pelvic exercise regime.

Hypoxic ischaemic encephalopathy (HIE) is a particularly serious complication which can lead to lasting brain damage in the infant or even death. In the study collective of Hoffmann et al. (2018 cases of shoulder dystocia) the incidence of HIE was $0.3 \%$ [21]. In 2011, Leung et al. [22] published a study which investigated the relationship between arterial umbilical cord blood gas values, Apgar score, HBDI, and HIE after shoulder dystocia. The Apgar score at 5 minutes proved to be a better indicator of cerebral impairment due to hypoxia than arterial umbilical cord $\mathrm{pH}$ and base excess, because it does not only consider the cardiopulmonary status but also takes the neurological status into account. The explanation for this suggested by the authors is, that compression of the carotid artery leads to local reduced perfusion of the neonatal brain. This prevents arterial blood from reaching the brain, and hypoxia prevents the removal of the products of anaerobic metabolism. Umbilical cord pH only shows the degree of acidosis in other parts of the circulation and does not properly indicate the extent of cerebral acidosis. In the study collective, only one infant $(0.5 \%)$ in the group with an HBDI of less than 5 minutes had HIE grade I. However, when the HBDI was longer than 5 minutes, the incidence of HIE was $23.5 \%$ [22].

A comparison of the German guideline on shoulder dystocia [8] and the guideline of the RCOG (Royal College of Obstetricians and Gynaecologists) [23] and of the ACOG (American Congress of Obstetricians and Gynecologists) [24] highlights a number of differences. The DGGG recommends offering the patient elective caesarean section if the estimated birth weight is $4500 \mathrm{~g}$ or above [8]. The RCOG recommends offering elective caesarean section only if the estimated neonatal birth weight is $4500 \mathrm{~g}$ or above and is combined with maternal diabetes mellitus [23]. The ACOG also supports this recommendation but proposes offering elective caesarean section when the birth weight is $5000 \mathrm{~g}$ or above, even if no maternal diabetes mellitus is present [24]. All 3 guidelines agree that, while previous shoulder dystocia does not constitute an absolute indication for caesarean section, elective caesarean section must be discussed with the patient $[8,23,24]$. If shoulder dystocia occurs, all 3 guidelines unanimously agree that the initial procedure should consist of a McRoberts' manoeuvre, if necessary, combined with suprapubic pressure $[8,23,24]$. The guideline of the ACOG suggests performing further manoeuvres to achieve internal rotation and the use of cleidotomy and the Zavanelli manoeuvre in severe cases but does not offer any specific 
recommendations [24]. The German guideline recommends performing additional manoeuvres to achieve internal rotation and delivery of the posterior arm but also does not provide additional recommendations on the procedure to follow if these additional manoeuvres fail [8]. The guideline of the RCOG [23] mentions the Gaskin manoeuvre (all-fours manoeuvre) as a possible additional manoeuvre, with a reported success rate of $83 \%$. If the McRoberts' manoeuvre fails, suggested third-line manoeuvres include internal rotation, delivery of the posterior arm, the Zavanelli manoeuvre and symphysiotomy. The RCOG expressly highlights the risk of postpartum haemorrhage and the potential for more serious birth injuries.

Both the German guideline and the guideline of the RCOG highlight forensic aspects. Both guidelines $[8,23]$ recommend that all measures undertaken are carefully recorded, including their timing and all staff involved. The RCOG gives even more precise specifications, suggesting that records must include the time of delivery of the head; the anterior shoulder at the time of the dystocia; the manoeuvres performed, their timing and sequence; maternal perineal and vaginal examinations; estimated blood loss, the time of delivery of the body; the Apgar score; umbilical cord $\mathrm{pH}$; postpartum care of the neonate; the staff in attendance and the time they arrived [23]. The RCOG guideline includes a form asking for these details to make documentation easier [23].

Both guidelines recommend that obstetric clinics have a risk management plan in place and that maternity clinics offer regular training to all birth attendants $[8,23]$. The RCOG goes even further than the DGGG and states how often such training should be absolved and what it should cover [23].

According to several studies [25,26], training significantly decreases the risk of brachial plexus injury, not only for shoulder dystocia. Moreover, training can help to improve confidence, particularly of younger colleagues, when confronted with such an event. But it is necessary that not only vaginal manoeuvres are practiced. Every obstetrician also needs to be familiar with the operative methods used to treat serious shoulder dystocia and be capable of using them in an emergency. Implementation of the recommendations of national guidelines is necessary to avoid liability and comprehensive documentation is particularly imperative.

\section{Conflict of Interest \\ $\nabla$}

None.

\section{References}

1 Gnirs J. Schulterdystokie. In: Schneider H, Husslein P, Schneider KTM, Hrsg. Geburtshilfe. 2. Auflage. Heidelberg: Springer; 2004: 836-852

2 Hadlock FP, Harrist RB, Sharman RS. Estimation of fetal weight with the use of head, body and femur measurements - A prospective study. Am J Obstet Gynecol 1985; 151: 333-337

3 Berle P, Misselwitz B. Mütterliche antepartale Risiken einer Schulterdystokie - Eine Analyse der HEPE aus 224744 reifen vaginalen Einlingsgeburten aus Schädellage der Jahre 2002-2008. Z Geburtsh Neonatol 2009; 213: 171-175
4 Stein W, Delfy A, Schmidt S. Prädiktion der Schulterdystokie - Ist eine Verbesserung der sonografischen Detektion einer fetalen Makrosomie unter Hinzuziehung maternaler Risikofaktoren möglich? Z Geburtsh Neonatol 2009; 213: 180-185

5 Hitchold T, Grewe J. Schulterdystokie - Risikofaktoren und Hinweiszeichen; Retrospektive Analyse an einem geburtshilflichen Kollektiv von 14913 Geburten mit 53 Schulterdystokien. Z Geburtsh Neonatol 2008; 212: $211-216$

6 Pohl K, Lack N, Knüppel $M$ et al. Schulterdystokie - eine vermeidbare Komplikation? Geburtsh Frauenheilk 2006; 67: PO_G_01_16

7 Hitschold T, Grewe J, Knob S. Schulterdystokie - Bedeutung der BIPThorax-Diskrepanz. Geburtsh Frauenheilk 2008; 68: FV_1_3

8 Deutsche Gesellschaft für Gynäkologie und Geburtshilfe (DGGG), Arbeitsgemeinschaft Medizinrecht (AGMedR). S1 Leitlinie: Empfehlungen zur Schulterdystokie - Erkennung, Prävention und Management aus Leitlinien der Gynäkologie und Geburtshilfe Band IV. Berlin: Verlag S. Kramarz; 2010: 143-148

9 Leung TY, Stuart O, Suen SSH et al. Comparison of perinatal outcomes of shoulder dystocia alleviated by different type and sequence of manoeuvres: a retrospective review. BJOG 2011; 118: 985-990

10 McFarland M, Langer O, Piper JM et al. Perinatal outcome and the type and number of maneuvers in shoulder dystocia. 1996. Int J Gynecol Obstet 1996; 55: 219-224

11 Paris AE, Greenberg JA, Ecker JL et al. Is an episiotomy necessary with a shoulder dystocia? Am J Obstet Gynecol 2011; 205: 217.e1-217.e3

12 Sandberg EC. The Zavanelli maneuver: 12 years of recorded experience. Obstet Gynecol 1999; 93: 312-317

13 Vollebergh JHA, van Dongen PWJ. The Zavanelli manoeuvre in shoulder dystocia: Case report and review of published cases. Eur J Obstet Gynecol Reprod Biol 2000; 89: 81-84

14 Goodwin TM, Banks E, Millar LKet al. Catastrophic shoulder dystocia and emergency symphysiotomy. Am J Obstet Gynecol 1997; 177: 463-464

15 Reid PC, Osuagwu FI. Obstetric case report: symphysiotomy in shoulder dystocia. J Obstet Gynecol 1999; 19: 664-666

16 O'Leary J, Cuva A. Abdominal rescue after failed cephalic replacement. Obstet Gynecol 1992; 80: 514-516

17 O'Shaughnessy MJ. Hysterotomy facilitation of the vaginal delivery of the posterior arm in a case of severe shoulder dystocia. Obstet Gynecol 1998; 92: 693-695

18 Hankins GD, Clark SL. Brachial plexus palsy involving the posterior shoulder at spontaneous vaginal delivery. Am J Perinatol 1995; 12 : 44-45

19 Schwenzer T. Die Schulterdystokie und ihre forensischen Aspekte. Gynäkologe 1994; 27: 222-228

20 Athukorala C, Middleton P, Crowther CA. Intrapartum interventions for preventing shoulder dystocia (Review). Cochrane Database Syst Rev 2006; 4: CD005543

21 Hoffmann MK, Bailit JL, Branch DW et al. A comparison of obstetric maneuvers for the acute management of shoulder dystocia. Obstet Gynecol 2011; 117: 1272-1278

22 Leung TY, Stuart O, Sahota DS et al. Head-to-body delivery interval and risk of fetal acidosis and hypoxic ischaemic encephalopathy in shoulder dystocia: a retrospective review. BJOG 2011; 118: 474-479

23 Royal College of Obstetricians and Gynecologists (RCOG). Shoulder dystocia - green-top guideline No.42.; 2. Edition; March 2012. http:// www.rcog.org.uk/files/rcog-corp/GTG\%2042_Shoulder\%20dystocia\% 202nd\%20edition\%202012.pdf; Stand: 2012

24 American Congress of Obstetricians and Gynecologists (ACOG). ACOG practice bulletin No. 40 - Shoulder dystocia. Int J Gynaecol Obstet 2003; 80: 87-92

25 Inglis SR, Feier N, Chetiyaar J et al. Effects of shoulder dystocia training on the incidence of brachial plexus injury. Am J Obstet Gynecol 2011; 204: $322-326$

26 Draycott TJ, Crofts JF, Ash JP et al. Improving neonatal outcome through practical shoulder dystocia training. Obstet Gynecol 2008; 112: 14-20

Deutschsprachige Zusatzinformationen online abrufbar unter: www.thieme-connect.de/ejournals/toc/gebfra. 